\title{
PUERICULTURA EM ENFERMAGEM E EDUCACÃO EM SAÚDE: PERCEPÇÃO DE MÃES NA ESTRATÉGIA SAÚDE DA FAMÍLIA
}

\author{
Child care in nursing and health education: mother's perception in family health strategy \\ Puericultura en enfermería y educación en salud: la percepción de las madres en la \\ estrategia de salud familiar
}

Viviane Mamede Vasconcelos

Mirna Albuquerque Frota²

Mariana Cavalcante Martins ${ }^{3}$

Márcia Maria Tavares Machado ${ }^{4}$

\section{RESUMO}

Objetivou-se descrever a vivência das mães sobre os cuidados prestados aos filhos, bem como a percepção destas em relação à consulta de puericultura. Realizou-se pesquisa-ação com onze mães de crianças menores de dois anos e utilizou-se a entrevista semiestruturada em visita domiciliária às mães, seguidas de consultas mensais de puericultura e estratégias de educação em saúde e de nova entrevista para avaliação da implementação das consultas. Após descrição e análise dos dados, emergiram as categorias: Construção da Competência para ser mãe; Alternativas e Tratamento da Doença; Aprendizado na Puericultura. As consultas favorecem o cuidado das mães ao filho, proporcionando saúde de qualidade, por meio da promoção da saúde e prevenção de doenças.

Palavras-chave: Mães. Cuidado da criança. Saúde da criança. Saúde pública.

\begin{abstract}
It was aimed to describe the experience of mothers on the care offered to their children, as well as their perception on child care consultation. A research action was carried out with eleven mothers of children under two years, we used the semi-structured interview in home visits to mothers, followed by monthly visits for child care and health education strategies, and new interviews to assess the implementation of consultations. After data's description and analysis, the categories emerged: Construction of Power to be a Mother, Alternatives and Treatment on the Disease; Learning in Child Care. Consultations favor the care of mothers with the child, providing quality health care through health promotion and disease prevention.
\end{abstract}

Keywords: Mothers. Child Care. Child Health. Public Health

\section{Resumen}

El objetivo fue describir la experiencia de las madres acerca de la atención a los hijos, así como su percepción sobre la consulta de puericultura. Se llevó a cabo la investigación / acción con once madres de niños menores que dos años, se utilizó la entrevista seme estructurada en las visitas domiciliarias a las madres, seguidos de visitas mensuales de puericultura y las estrategias de educación, salud y nuevas entrevistas para evaluar la aplicación de consultas. Después de describir y analizar los datos, surgieron las categorías: Construcción de la competencia para ser madre, Alternativas y tratamiento delante de la enfermedad; Aprendizaje en la Atención de Niños. Las consultas promueven la atención de las madres al hijo, proporcionando la atención de calidad a través de la promoción de la salud y de la prevención de enfermedades.

Palabras clave: Madres. Cuidado del Niños. Salud del Niño. Salud Pública.

\footnotetext{
${ }^{1}$ Enfermeira. Doutoranda em Enfermagem - UFC. Bolsista FUNCAP. Fortaleza-CE. Brasil. E-mail: vivienfermagem@hotmail.com²Enfermeira. Doutora em Enfermagem. Professora Adjunta do Curso de Graduação em Enfermagem e do Mestrado em Saúde Coletiva da Universidade de Fortaleza - UNIFOR. Fortaleza - CE. Brasil. E-mail: mirnafrota@unifor.br; ${ }^{3}$ Enfermeira. Doutora em Enfermagem. Docente do Curso de Graduação em Enfermagem da Faculdade Integrada da Grande Fortaleza - FGF.Canindé-CE. Brasil. E-mail: marianaenfermagem@hotmail.com; ${ }^{4}$ Enfermeira. PhD em Saude Publica. Professora Adjunta da Faculdade de Medicina da Universidade Federal do Ceara, e da Pos-graduacao em Saude Coletiva da UFC.Senador Pompeu - CE. Brasil. Email: marciamachado@ufc.br
} 


\section{INTRODUÇÃO}

A criança é um ser vulnerável que necessita de assistência sistemática e periódica. Para tanto, a consulta de puericultura tem o papel de acompanhar a criança saudável na expectativa de reduzir a incidência de enfermidades, elevando as oportunidades para alcançar todo o potencial por meio do crescimento e desenvolvimento ${ }^{1}$, logo são preconizadas sete consultas durante o primeiro ano de vida, duas consultas dos 12 aos 24 meses e uma consulta anual dos 36 aos 72 meses $^{2}$.

Promover e recuperar a saúde e o bem-estar da criança é prioridade na assistência à saúde infantil, a fim de garantir crescimento e desenvolvimento adequados nos aspectos físico, emocional e social. Para que a promoção ocorra de forma satisfatória, a consulta de puericultura deve ser desenvolvida com plenitude, no qual o profissional da saúde deve conhecer e compreender a criança no ambiente familiar e social, além das relações e interação com o contexto socioeconômico, histórico, político e cultural $^{3}$.

Mediante a vivência de uma das autoras deste estudo, percebeu-se que a maioria dos profissionais da Estratégia Saúde da Família (ESF), que prestava assistência à comunidade, priorizava 0 atendimento à criança doente. Ante a essa realidade, evidenciou-se a necessidade da realização da consulta de puericultura e, por meio desta, a orientação sobre o cuidar do filho e a detecção precoce de alterações no crescimento/ desenvolvimento infantil e distúrbios nutricionais, utilizando como auxílio as estratégias educativas em saúde.

Ao reconhecer o valor das ações educativas, mencionase o fato de que promoção da saúde é um processo de capacitação da comunidade para atuar na melhoria da qualidade de vida e saúde, incluindo maior participação no controle deste processo. Para que seja efetivo, deve-se repensar sob a perspectiva da participação social, compreender que as reais práticas somente apresentam lugar entre sujeitos sociais e considerar a educação em saúde como estratégia para a constituição de indivíduos que se movimentam em direção a um projeto de vida libertador 4 .

A Promoção da Saúde ultrapassa o estilo de vida saudável, na direção do bem-estar global, não sendo responsabilidade exclusiva do setor saúde ${ }^{5}$. A mãe, aliada ao profissional da saúde, deve comprometer-se em prestar assistência ao filho, estando este sadio ou doente. Neste sentido, a puericultura contribui para estratégias de Promoção da Saúde na sala de espera e durante a consulta, proporcionando acompanhamento do binômio mãe-filho, de forma a ensejar troca de experiências e superação de dificuldades.

Em face do exposto, objetivou-se descrever a vivência das mães sobre cuidados prestados aos seus filhos, bem como a percepção destas em relação à consulta de puericultura.

\section{METODOLOGIA}

Realizou-se pesquisa-ação, por exigir o envolvimento ativo do pesquisador e a ação por parte da clientela-alvo, por meio de avaliação diagnóstica, aç̃es educativas e avalição final ${ }^{6}$.

A pesquisa foi composta de 11 mães primíparas de crianças menores de dois anos, assistidas pela equipe da ESF, das localidades de Irapuá e Baixio, distritos de Croatá - Ceará. As mães tinham idade de 16 a 21 anos, sendo seis adolescentes. Apenas duas tinham o ensino médio incompleto, as demais, não tinham concluído o ensino fundamental, variando da segunda série a nona série. Todas eram profissionais do lar; três solteiras; quatro, casadas; e quatro, em união consensual, com renda familiar de $\mathrm{R} \$ 58,00$ a $\mathrm{R} \$ 380,00$.

Ressalta-se que as primíparas foram as informantes da pesquisa por se inserirem no âmbito em que mudanças, ocasionadas pela maternidade do primeiro filho, requerem respostas cognitivas, emocionais e comportamentais, que não integram o repertório comportamental da mulher, exigindo adaptações específicas e maior atenção ${ }^{7}$; e as crianças menores de dois anos por considerar que nessa faixa etária devem ser realizadas com maior frequência as consultas de puericultura².

Os passos de coleta dos dados seguiram o percurso metodológico da pesquisa-ação, perpassando três momentos. A primeira etapa foi o Diagnóstico situacional, em que foi realizada a entrevista semiestruturada, durante visita domiciliária, contendo as questões norteadoras: como a senhora faz para cuidar do seu filho diariamente? Quando seu filho adoece, qual sua conduta?

A segunda etapa foi a Intervenção, com a realização das consultas mensais de puericultura e sessões educativas, até então não realizadas nas localidades referidas. Essas consultas foram embasadas nas etapas: 0 enfermeiro recebe a criança e a mãe; procede aos cumprimentos habituais; observa o comportamento e relacionamento estabelecido entre a criança e a mãe; verifica no prontuário e/ou na ficha de atendimento informações socioambientais, dados da consulta anterior, se for pertinente, e informações registradas durante o preparo da criança, como peso, estatura e perímetro cefálico, bem como queixas maternas, dúvidas, ansiedades, inquietações, favorecendo o bem-estar do binômio mãe-filho².

Após quatro sucessivas consultas, houve maior aproximação com as famílias, conhecimento da realidade, possibilitando atenção integral, dentro das condições socioeconômicas e culturais, evitando a automedicação e 0 agravamento de doenças, algumas vezes preveníveis.

Antes de cada consulta, na sala de espera com todas as mães, foi realizada a sessão educativa, baseando-se no pressuposto de que a educação para a saúde deve constituir parte essencial da promoção da saúde e prevenção de doenças, por meio da perspectiva dialógica.

Foram abordadas temáticas que emergiram das necessidades das mães durante as consultas de puericultura, 
destacando o Aleitamento Materno, a Alimentação Complementar após seis meses, a Caderneta da Criança: Crescimento e Desenvolvimento Infantil, a Prevenção de quedas e acidentes, como forma de atingir a proposta da ESF, no aspecto da Promoção da Saúde.

E, por fim, a terceira etapa foi a Apreensão - Avaliação Final, executada por meio da entrevista semiestruturada final, composta das questões: qual sua opinião sobre a consulta de puericultura? Como está o cuidado com seu filho após as consultas? 0 que foi para você participar das ações educativas?

As entrevistas (Diagnóstico situacional e Avaliação final) que aconteceram nas casas de apoio, suporte para as consultas da Estratégia Saúde da Família, foram individuais e gravadas mediante autorização prévia, possibilitando melhor transcrição das falas, retratando de forma fiel o contexto estudado.

Na organização dos dados, utilizou-se a técnica de análise temática, cujo método caracteriza-se pela descrição das falas, documentação, identificação e categorização, seguida da saturação de ideias, identificação de significados similares, diferentes e, por fim, síntese do pensamento, análise da configuração, interpretação e formulação criativa dos achados ${ }^{8}$, do qual emergiram as categorias: Construção da Competência para Ser Mãe, Alternativas e Tratamento da Doença e Aprendizado na Puericultura.

A pesquisa considerou os preceitos éticos de confidencialidade, sigilo e anonimato e foi aprovada pelo Comitê de Ética, da Universidade de Fortaleza, sob o parecer de número 07520805-9, segundo a Resolução n 196/96, do Conselho Nacional de Saúde. É válido destacar o fato de que as mães foram identificadas por cognomes, como: M1, M2, [...], M11, com o intento de preservar o anonimato.

\section{RESULTADOS E DISCUSSÃO}

Após transcrição das falas e análise, estas foram agrupadas por convergência, o que possibilitou a classificação do conteúdo em totalidade, emergindo três categorias temáticas.

\section{Construção da competência para ser mãe}

É sabido que mães primíparas podem apresentar dificuldade em relação ao cuidado ao filho, em especial nos primeiros dias de vida, desencadeando momentos de incertezas e angústias, sobretudo se a criança apresentar comportamento diferenciado.

Tem muita coisa que eu não sei. Uma vez ele estava sentindo alguma coisa, chorando, chorando, chorando [...] eu não sabia o que era, fiquei aperreadinha! (M7)

No começo eu não sabia de quase nada, teve uma vez que ele tava com dor de cólica e eu não sabia o que fazer, o que ele estava sentindo. (M11)
Eu nunca cuidei de neném [...] aí é difícil. Principalmente, quando ele adoece! Em primeiro lugar é ele! (M4)

Inquietações e dúvidas vivenciadas pelas mães são comuns diante da primeira gestação, por isso torna-se fundamental a atenção profissional não somente na consulta de pré-natal, sobretudo na consulta de puericultura, diante do fato de que muitos dos anseios podem ser reduzidos, permeados por orientações plausíveis para com a mãe.

A maioria das diferenças no comportamento maternal, associadas ao primeiro contato com a criança, desaparece com o tempo e existem consideráveis evidências de que prejuízos sejam causados à mãe e, consequentemente, à criança. Para tanto, diante dessa inexperiência de ser mãe, fatores influenciadores envolvem a díade mãe-criança, permeados por formações cultural e social, perpassando por gerações, como no caso das avós da criança, bem como a experiência de cuidar dos irmãos, dentre outros ${ }^{9}$.

Aprendi tudo que eu sei com a minha mãe [...] eu não sabia de nada [...] é meu primeiro filho. (M2)

Não [...] Eu acho que tudo enquanto eu sei um pouquinho [...] Eu tive ajuda da minha sogra ensinando, da mãe. Tinha alguma coisa que eu não sabia do umbigo dele, da barriga dele, quando eu não sabia perguntava [...] aí elas ajudavam! (M8)

Estudo realizado com gestantes evidenciou incertezas no contexto de cuidar do filho, caracterizando insegurança, expondo a necessidade do auxílio dos membros da família mais próximos, podendo ser a mãe da gestante ou a sogra, que auxiliam na assistência à criança e financeiramente ${ }^{10}$.

Na zona rural, sobretudo na região Nordeste, é comum a filha mais velha cuidar dos irmãos mais novos, pois são constituídas famílias de grande prole e não possuem condições de custear cuidador $^{11}$, o que é evidenciado nos relatos:

Muita coisa eu já sabia, porque eu aprendi cuidando dos meus irmãos! (M9)

Tem muita coisa que eu já sabia na hora de cuidar de menino pequeno, porque eu sou a mais velha e eu cuidei dos meus irmãos pequenos, aí fui aprendendo, na hora do meu eu já sabia de tudo! (M10)

Mães que experienciaram o cuidado aos irmãos tendem a sobressair-se na atenção ao filho, em atividades relacionadas ao banho e à habilidade em cuidar; porém, por possuírem conhecimentos primitivos e empíricos, podem apresentar limitações no cuidar referentes à alimentação adequada e 
prevenção de doenças, associando o cuidar à realização de necessidades humanas básicas, como alimentação, higiene e medicação quando necessário.

Dou banho [...] dou remédio às vezes quando precisa e dou comida. (M1)

Minha mãe me ajuda a cuidar [...] Eu banho ela, dou leite. Mais o que eu não sabia minha mãe me ensinou! Eu já cuidava dos meus irmãos [...] Banho quem deu primeiro foi minha madrinha, depois foi a mãe, aí pronto agora sou eu que dou! (M9)

Eu cuido bem dele, dou comida quando está chorando e quando está com dor de barriga eu dou gotinha a ele. (M2)

0 cuidado assistencialista pode ser consequência do cuidado prestado pela enfermeira durante a consulta de puericultura. Um estudo observacional realizado com enfermeiras durante a consulta de puericultura verificou que, embora as enfermeiras reconheçam a importância da puericultura, as ações desenvolvidas em saúde da criança são mecanizadas, reproduzindo a fragmentação no modo como se produz o cuidado, não sendo identificadas ações que atendam às necessidades singulares das crianças em seu processo de crescimento e desenvolvimento, objetivo da prática de puericultura $^{12}$.

0 cuidado deve ser uma atitude relacionada ao sentimento de um ser humano para com o outro, em respeito à dimensão existencial do ser e valorizando a expressão da experiência de vida de ambos no momento do cuidar. 0 cuidado ocorre na intersubjetividade humana, em uma relação de encontro seleto entre profissional e ser cuidado, em movimento de complementaridade de ações, reações e sentimentos ${ }^{13}$.

Para tanto, o cuidado dispensado pelas mães deve perpassar o âmbito biológico, envolvendo-se na tríade biopsicossocial, na qual deve ser estigada pelos puericultores, em especial o enfermeiro, aliando o saber científico ao saber popular, construindo assim um cuidado plausível e eficaz e consequente aprimoramento na competência de ser mãe no processo do crescimento e desenvolvimento.

\section{Alternativas e tratamento da doença}

Em decorrência das incertezas sobre o cuidado da mãe prestado à criança e de influências familiares, é comum na zona rural se utilizar de opções de cura de doenças por meio de plantas medicinais, o que está intrinsecamente relacionado à cultura, como resultado das experiências de gerações que foram transmitidas por meio de aprendizagem consciente ou inconsciente. 0 uso da medicina complementar está associado, algumas vezes, à automedicação.
Ela só adoeceu uma vez, eu dei chá de palmerinha e mandei rezar, aí ela ficou boa! (M9)

Quando ele está com febre, eu dou paracetamol, A.A.S. [...] Quando é uma gripe, o povo manda dar banha de galinha, uma vez eu dei [...] e coloco soro no nariz quando está entupido. (M4)

A fitoterapia trata das várias enfermidades que aflingem a população, têm aplicação consagrada, por médicos ou não, e desde a Antiguidade é repassada entre os familiares. Diante da credibilidade da fitoterapia, caracterizada como prática integrativa, esta se consolida a cada dia no contexto do Sistema Único de Saúde (SUS) e é implantada com nível primário de atenção ${ }^{14}$.

É práxis do povo nordestino o trabalho de rezadeiras, parteiros, raizeiros, curandeiros, todos convergindo para a cura. 0 emprego de plantas medicinais, assim como a homeopatia, recomendado pela Agência Nacional de Vigilância SanitáriaANVISA, para programas de atenção primária à saúde, pode ser alternativa terapêutica atrelada ao baixo custo, fácil aquisição e que se compatibiliza com o aspecto cultural dos povos $^{15}$.

Os profissionais da saúde devem, portanto, valorizar a cultura da população assistida, pois são ideias embutidas de antepassados que perpassam a cada geração. 0 conhecimento das crendices e práticas populares relacionadas ao processo saúde-doença é essencial para que os profissionais se familiarizem com os grupos com que trabalham e aprendam a lidar com o valor cultural de cada indivíduo. Portanto, ressaltase a associação entre hábitos culturais com os saberes científicos.

Outro aspecto comum no cuidado da mãe ao filho doente é a automedicação, fator esse justificado por elas pelo difícil acesso ao serviço de saúde, no qual o hospital é referência apenas em casos mais graves e a alternativa de medicar-se sem prescrição ou fitoterapia apresenta resolubilidade.

Assim, uma vez deu uma dor de ouvido muito forte, porque entrou água, aí eu levei no hospital. Outra vez ele estava doente eu dei chá de hortelã. Quando ele está muito mal, gripado, eu levo para o hospital para tomar aerossol. (M10)

Quando ele fica sentindo alguma coisa, eu dou umas gotinhas de paracetamol a ele [...] se não resolve eu procuro o médico [...] porque a única coisa que eu dou é o paracetamol! (M7)

Eu levo para o médico [...] às vezes quando ele está com gripe, febre, eu dou umas gotinhas de dipirona, dou também chá e banho de eucalipto! (M8) 
Nas localidades investigadas, ter o hospital como referência, ao invés da ESF, é preocupante, pois essa estratégia tem papel fundamental na estruturação do modelo de atenção que priorize a intersetorialidade, a descentralização e, sobretudo, o rompimento do comportamento passivo das unidades básicas de saúde, entendendo o indivíduo como singular e parte integrante do contexto amplo, que é a família e a comunidade.

Após a entrevista diagnóstica, a fase de intervenção composta pelas consultas de puericultura e sessões educativas, realizou-se a entrevista final para verificar a apreensão do conhecimento, com características de feedback com as mães, estratégia de avaliação em que se obtêm informações acerca de atitudes, comportamentos, indicandoos como impactantes, com o objetivo de atingir melhor desempenho. Salienta-se que este procedimento deveria ser presença nas atividades do profissional da saúde, pois é por meio desta técnica que se desvenda de forma positiva ou negativa o significado da orientação fornecida.

\section{Aprendizado na puericultura}

A Educação em Saúde tem instrumento de constituição popular nos serviços de saúde e, ao mesmo tempo, de aprofundamento da intervenção da ciência na vida cotidiana das famílias e da sociedade ${ }^{16}$.

Nesse sentido, após a realização das consultas de puericultura, acompanhadas de sessões de Educação em Saúde, as mães relataram que ainda tinham muito a aprender e que 0 acompanhamento foi primordial para que apreendessem acerca do cuidado ao filho.

Fazia o que a mãe, a sogra dizia. Hoje, eu já sei cuidar melhor sozinha. Quando ela tiver seis meses é para dar papa, mama [...] sei o que ela vai ter que fazer mais ou menos com cada idade [...] Aprendi muita coisa! (M3)

Está bem melhor, porque a gente cuida de um jeito, aí os profissionais ensinam a cuidar melhor. A gente nem sabe de tudo porque é o primeiro ainda! Quando eu comecei a vir, percebi que não sabia de nada e tenho muito para aprender. (M4)

Aprendi sobre alimentação, quando meu filho está doente, como cuidar dele [...] dar mais atenção, não cuidar só da casa e deixar ele de lado, porque tem muita mãe que não dá atenção aos filhos. (M11)

Diante do exposto, comprovou-se que houve empoderamento, na medida que verificou-se um discurso coeso e coerente com o que foi exposto e preconizado, favorecendo a um processo de reflexão e, consequentemente, de for talecimento do cuidado inerente à díade mãe-filho.
Diante desse processo de reflexão, as mães enfocaram a alimentação como fator primordial para a saúde da criança, corroborando a literatura ao revelar que o crescimento e 0 desenvolvimento favoráveis da criança estão relacionados à alimentação adequada. Portanto, alimentação saudável não se caracteriza como de alto custo, mas rica em nutrientes que possam atender às necessidades nutricionais da criança, prevenindo patologias de reversão difícilit .

Aprendi muita coisa, principalmente sobre alimentação [...], aprendi que não precisa ter muito dinheiro para alimentar bem meus filhos. (M7)

Eu não dava "comida de panela" para ele, agora eu estou dando, melhorei na alimentação dele, eu dava mais era Danone e biscoito recheado. Se eu tiver outro filho já vou cuidar melhor porque o primeiro a gente não sabe mesmo. (M5)

Observou-se a necessidade de realizar uma consulta completa, direcionando atenção e carinho à criança, sobretudo prestando cuidado humanizado, em especial, por serem primíparas. As consultas devem ocorrer em forma dialogal, dessa forma, as mães podem fazer indagações, expressar dúvidas e discorrer acerca da realidade diária que vivenciam. Assim, os profissionais da saúde procedem, de modo mais direcionado, às orientações primordiais ao cuidado às crianças, intervindo quando preciso.

Achei boa porque você conversava com a gente, cuidava bem direito. Para ir para outro município élonge e tendo consulta todo mês fica mais fácil. (M5).

Eu gostei muito das consultas! Pela simpatia, atenção [...] (M11)

Foi bom demais, porque, assim, a gente aprendeu muitas coisas. A minha filha foi bem examinada [...] (M3)

As ações humanizadas desenvolvidas pela equipe de saúde são percebidas por meio de atitudes e comportamento dos profissionais, associados à percepção dos sujeitos a respeito dos comportamentos de conotação vocacional (gostar do que fazem), ou associados à competência teórica e técnica adequada ${ }^{18}$.

Portanto, percebeu-se a necessidade da implantação da consulta de puericultura, conforme os preceitos do Ministério da Saúde, pois a consulta favorece o cuidar das mães ao filho, superando incertezas, proporcionando, consequentemente, saúde de qualidade 
à criança, por meio da promoção da saúde e prevenção de doenças, por estratégias educativas.

\section{CONSIDERAÇÕES FINAIS}

A consulta de puericultura repercutiu de forma satisfatória na comunidade investigada, pois foi possivel aprimorar conhecimentos sobre alimentação e cuidados gerais à criança, em especial, por serem primíparas, pois encontravamse repletas de incertezas quanto ao cuidado ao filho, mesmo com apoio familiar.

Dessa forma, as consultas existiram visando a orientar às mães quanto ao cuidado à criança saudável, evitando o estigma de que deve ser assistida, apenas, se acometida por alguma patologia. Assim, para gestores e equipes de saúde, este é um momento oportuno para proporem estratégias de promoção da saúde e prevenção de doenças, não com foco na cura. Evidenciouse, então, que se deve orientar a população quanto à importância da avaliação constante do crescimento e desenvolvimento infantil, repercutindo na redução de doenças e agravos.

A implantação da consulta de puericultura existe há dois séculos, porém ainda existem ESF que não realizam. Por isso, esta pesquisa sinaliza para a sua realização, conforme preconizado pelo Ministério da Saúde, como ação da atenção básica, a fim de evitar a superlotação da rede terciária do municíio, melhorar indicadores de saúde, pois as crianças são seres vulneráveis que necessitam estar em constante assistência, de forma a evitar agravos irreversíveis à saúde, assim como ampliar o conhecimento das mães quanto ao cuidado ao filho e ainda proporcionar qualidade de vida a essas crianças.

Logo, o profissional precisa aproximar-se das mães $\mathrm{e}$ da comunidade como um todo, realizando atividades centradas na atenção primária, desenvolvendo estratégias de Educação em Saúde, com foco na promoção da saúde e no "empoderamento" do indivíduo.

\section{REFERÊNCIAS}

1. Campos RMC, Ribeiro CA, Silva CV, Saparolli ECL. Consulta de enfermagem em puericultura: a vivência do enfermeiro na estratégia de saúde da família. Rev Esc Enferm USP. 2011; 45(3): 566-74.

2. Ministério da Saúde (BR). Saúde da criança: acompanhamento do crescimento e desenvolvimento infantil. Brasíl(DF); 2002.

3. Del Ciampo LA, Ricco RG, Daneluzzi JC, Del Ciampo IRL, Ferraz IS, Almeida CAN. 0 Programa de Saúde da Família e a puericultura. Cienc Saude Colet. 2006; 11(3): 739-43.

4. Czeresnia D, Freitas CM. Promoção da saúde: conceitos, reflexões, tendências. Rio de Janeiro: Fiocruz; 2003.

5. Lefevre F, Lefevre AMC. Promoção de Saúde: negação da negação. Rio de Janeiro: Vieira \& Lent; 2004.
6. Thiollent M. Metodologia da pesquisa-ação. São Paulo: Cortez; 2003.

7. Oliveira C, Pedrosa AA, Ramos MM, Monteiro S, Canavarro MA. Impacto do nascimento de um filho, percepção neonatal e adaptação na transição para a maternidade. Rev lber Psicol [periódico on-line]. 2005; [citado 2009 abr 14]; 10(2). Disponível em: http://www.fedap.es/lberPsicologia/ marcoip.htm.

8. Minayo MC. A pesquisa social: teoria, método e criatividade. Petrópolis(RJ): Vozes; 2010.

9. Hrdy SB. Mãe natureza: uma visão feminina da evolução: maternidade, filhos e seleção natural. Rio de Janeiro: Campus; 2001.

10. Frota MA, Barbosa LC, Albuquerque CM, Sousa Filho OA, Martins MC. Percepção da gestante sobre desnutrição infantil: enfoque nas particularidades da gestação. Rev Bras Promoc Saude. 2009; 22(2): 107-12.

11. Frota MA, Nogueira ATSN, Machado JC, Martins MC. Vivência sociocultural de crianças em uma comunidade rural: um estudo etnográfico. ReTEP. 2010; 2(1): 33-37.

12. Assis WDA, Collet N, Reichert APSI, Sá LD. Processo de trabalho da enfermeira que atua em puericultura nas unidades de saúde da familia. Rev Bras Enferm. 2011; 64(1): 38-46.

13. Cunha PJC, Zagonel IPS. A relação dialógica permeando o cuidado de enfermagem em UTI pediátrica cardíaca. Rev Eletr Enferm [on-line] 2006; [citado 2008 abr 12]; 8 (2). Disponível em: http://www.fen.ufg.br/revista/ revista8_2/v8n2a14.htm.

14. Ministério da Saúde (BR). Sistema de Informação da Atenção BásicaSIAB 2006. [citado 2007 set 25]; Disponível em: http://wnw. datasus.gov.br.

15. Medeiros LCM, Machado, FM, Azevedo GAV, Sousa SR. As práticas populares de cura utilizadas por rezadores no povoado brejinho, município de Luiz Correia - PI. Esc Anna Nery. 2007; 11(1):58-65.

16. Vasconcelos EM. Educação ppular e a atenção à saúde da família. São Paulo: Hucitec; 2001.

17. Martins MC, Ximenes LB, Casimiro CF, Silveira VG, Frota MA. Estratégias educativas com enfoque nos hábitos alimentares de crianças: enfoque nos alimentos regionais. Cogitare Enferm. 2009; 14(3): 463-69.

18. Faquinello P, Higarashi IH, Marcon SS. 0 atendimento humanizado em unidade pediátrica: percepção do acompanhante da criança hospitalizada. Texto\&Contexto Enferm. 2007; 16(4): 609-16. 